\title{
Transactional or Transformational? Leadership Preferences of Division III Athletic Administrators
}

\author{
Laura J. Burton \\ University of Connecticut \\ Jon Welty Peachey \\ Texas A\&M University
}

\begin{abstract}
Leadership research within sport management has yielded inconsistent results when examining transactional and transformational leadership. In addition, there has been a paucity of research comparing leadership behaviors between men and women based on leadership style. Therefore, this study examined whether leadership style (transactional, transformational) led to more positive perceptions of organizational outcomes in intercollegiate athletic administration and whether gender of the leader influenced these perceptions of leaders. Ninety-eight Division III athletic directors evaluated either a male or female transactional leader or a male or female transformational leader on extra effort, effectiveness, and satisfaction. Findings indicated transformational leadership was related to more positive organizational outcomes, specifically extra effort and satisfaction. However, gender of the leader did not influence these perceived outcomes.
\end{abstract}

Aside from a few earlier research endeavors (Doherty, 1997; Doherty \& Danylchuk, 1996; Kent \& Chelladurai, 2001; Wallace \& Weese, 1995; Weese, 1996) there has been a paucity of research in sport management, and intercollegiate athletic administration in particular, examining the differences between transactional and transformational leadership, specifically leader effectiveness when comparing male and female athletic directors. Leadership behavior has been identified as having significant influence on the success of an organization. In the sport and intercollegiate context, transformational leadership has been associated with more positive organizational outcomes, such as job satisfaction, affective commitment, altruistic behavior, and extra effort, as well as to perceived leader effectiveness (Choi, Sagas, Park \& Cunningham, 2007; Doherty \& Danylchuk, 1996). However, results have been inconsistent. For example, Weese (1996) reported no relationship between transformational leadership and organizational effectiveness within intercollegiate athletic conferences. 
Current examinations of leadership style have suggested that women demonstrate more transformational leadership behaviors (Eagly, Johannesen-Schmidt, \& van Engen, 2003), and were also perceived as more effective when acting as transformational leaders (Eagly \& Carli, 2003; Powell, Butterfield, \& Bartol, 2008). Within intercollegiate athletic administration leadership, however, the role of athletic director continues to be dominated by men (Acosta \& Carpenter, 2008). Therefore, we sought to determine whether leadership style (transactional or transformational) led to more positive perceptions of organizational outcomes in intercollegiate athletic administration and whether gender of the leader influenced these perceptions of leaders.

\section{Transformational vs. Transactional Leadership}

A substantial body of research has emerged over the last 20 years examining transformational-transactional leadership theory (Judge \& Piccolo, 2004). Burns (1978) was the first scholar to conceptualize transformational and transactional leadership, positing that the principal difference between the two styles was in what leaders and followers offer one another. In Burns' view, transformational leaders provide a purpose that transcends short-term goals and recognizes the higher order needs of followers. In contrast, transactional leaders view the proper exchange of resources as paramount. Thus, transformational leadership results in followers identifying with the needs of the leader, while a transactional leader will give subordinates something they want in exchange for something the leader desires (Kuhnert \& Lewis, 1987). Transactional leadership was seen as similar to the traditional study of leader behavior in business management and sport management over the previous four decades, whereas transformational leadership was a "new leadership" approach (Bryman, 1992; Doherty, 1997).

Bass (1985) then developed his transformational leadership theory based on Burns' (1978) initial conceptualization. He subsequently identified four characteristics of transformational leaders: 1) Charisma-providing vision and a sense of mission, instilling pride, trust and respect; 2) Inspiration-communicating high expectations, using symbols to focus efforts, expressing important purposes in simple ways; 3 ) Intellectual stimulation-promoting intelligence, rationality and careful problem solving; and 4) Individualized consideration-giving personal attention, treating each employee individually, coaching and advising (Bass, 1990). In essence, then, transformational leadership is characterized by leaders who "motivate subordinates to transcend their own self-interests for the good of the group or organization" (Powell et al., 2008, p. 159) through the use of high performance standards.

On the other hand, Bass (1990) defined transactional leadership as the process of managing by contract and reward, and on clarifying responsibilities of subordinates and then evaluating how successfully those responsibilities are carried out. Transactional leadership is characterized by 1) Contingent reward-establishing contracts and exchange of reward for effort; 2) Active management by exception-watching and searching for deviations from rules and standards, then taking corrective action; 3) Passive management by exception-intervening only if standards are not met; and 4) Laissez-faire_-abdicating responsibilities, avoiding making decisions. 
As mentioned previously, researchers have generally found that transformational leadership is associated with more positive organizational outcomes. For example, Choi et al. (2007) had coaches in five major NCAA conferences rate their athletic directors, and discovered that transformational leadership was linked to coaches' job satisfaction, affective commitment, and altruistic behavior. In another study, second- and third-tier athletic department personnel were asked to rate their athletic directors on transformational leadership behaviors (Kent \& Chelladurai, 2001). These researchers found that transformational leadership led to greater organizational commitment, specifically to feelings of attachment, identification and involvement with the organization.

Doherty and Danylchuk (1996) conducted a study in the Ontario University system, and found a predominantly transformational leadership profile exhibited by athletic administrators, as rated by their coaches. Specifically, there was a strong positive relationship between coaches' perception of leader effectiveness and the transformational leadership displayed by their athletic administrators, particularly related to the charisma and individualized consideration dimensions of transformational leadership. In addition, a negative relationship was identified between leader effectiveness and management by exception (passive) and laissez-faire leader behaviors. Finally, there was a positive association between the individualized consideration dimension of transformational leadership and extra effort stimulated by the leader, and a negative association between management by exception (passive) and laissez-faire leader behaviors and extra effort.

In the business management literature, Judge and Piccolo (2004) conducted a comprehensive meta-analysis of the transformational, transactional, and laissezfaire leadership literatures. They found that, across studies, transformational leadership behavior was more positively associated with leader effectiveness and follower satisfaction with the leader than transactional or laissez-faire leadership (Judge \& Piccolo, 2004). In addition, a recent meta-analysis of the organizational leadership research found that overall, transformational leaders were more effective than transactional leaders in guiding team processes and effecting positive organizational performance (Stewart, 2006). Thus, we advance that in the intercollegiate athletics context:

Hypothesis 1: Transformational leadership style, when compared to transactional approaches, will lead to more positive perceptions of organizational outcomes (i.e., extra effort, satisfaction, and effectiveness).

\section{Role Congruity Theory and Evaluation of Female Leaders}

When considering leadership behavior, specifically evaluation of female leaders, gender-role stereotyping and the influence of such stereotyping must be considered. Eagly (2007) noted that women suffer a disadvantage in leadership as a result of prejudice against female leaders and resistance when women occupy leadership roles. Role congruity theory explains that the underrepresentation of women in leadership positions may be the result of gender-role stereotyping of leadership positions (Eagly \& Karau, 2002). Gender-role stereotyping is understood through social role theory, which explains that there are qualities and behavioral tendencies 
believed to be desirable for each gender, as well as expectations regarding the roles men and women should occupy. Communal characteristics are often used to describe women, and they include being affectionate, helpful, kind, sympathetic, interpersonally sensitive, nurturing, and gentle (Eagly, 1987; Eagly, Wood, \& Diekman, 2000). Agentic characteristics are typically used to describe men, and include being aggressive, dominant, forceful, self-confident and self-sufficient (Eagly, 1987; Eagly, Wood, \& Diekman, 2000). Prescriptive gender role stereotypes indicate women should behave in more communal roles and not in agentic roles and men should behave in more agentic roles and not communal roles (Eagly \& Karau, 2002; Heilman, 2001). Role congruity theory, following the tenets of social role theory, proposes that a prejudice exists against potential female leaders because leadership ability is more stereotypically attributed to men (agentic) than to women (communal). Women are at a disadvantage in obtaining leadership positions because they are perceived as not having the stereotypical skills necessary to be leaders, and if women are in leadership positions they are not favorably evaluated in those positions because they are violating stereotypical gender norms applied to women (Eagly \& Karau, 2002).

Within business management, women, compared with men, have faced greater barriers when entering leadership roles, as leaders are perceived as requiring more agentic than communal traits (Powell, Butterfield, \& Parent, 2002; Schein, 2001) and are often unfavorably evaluated if they espouse more "masculine" (agentic) traits to be successful in leadership roles (Eagly \& Karau, 2002; Heilman, 2001). This prejudice against female leaders is more compelling when women are evaluated in male dominated settings or when evaluated by men (Eagly \& Carli, 2003). Interestingly though, there is evidence this "role congruity" issue may be mediated by leadership style as women leaders have been rated higher than men when they exhibit transformational leadership (Eagly \& Carli, 2003, Powell et al., 2008).

Transformational leadership behavior, as noted earlier in this paper, was more positively associated with leader effectiveness (Judge \& Piccolo, 2004). In addition, transformational leadership has been noted to be more congruent with a stereotypical feminine gender role and transactional leadership has been associated with a stereotypical masculine gender role (Powell et al., 2008). Female leaders have been recognized as demonstrating more transformational leadership behaviors than men (Eagly, Johannesen-Schmidt, \& van Engen, 2003), and have been perceived as more effective when acting as transformational leaders (Eagly \& Carli, 2003; Powell et al., 2008). This also holds in athletic administration settings (Doherty, 1997). Thus, transformational leadership behavior has been considered to have more communal characteristics, specifically within "individualized consideration" behaviors (Eagly, 2007). Additional research has noted that agreeableness was positively related to transformational leadership and agreeableness was related to a leader's warmth, kindness, gentleness, and cooperativeness; traits strongly linked to the stereotypical feminine gender role (Powell et al., 2008).

In contrast, male leaders have been identified as demonstrating more transactional leadership behaviors (Eagly \& Carli, 2003), but men were not perceived as more effective when demonstrating transactional leadership behavior (Eagly \& Carli, 2003; Powell et al., 2008). This has also been noted within sport management literature, as female athletic directors and associate athletic directors were evaluated as demonstrating more transformational leadership behaviors in comparison with male athletic directors and associate athletic directors (Doherty, 1997). Women 
may be perceived as having a leadership advantage over men as a result of demonstrating more transformational leadership behaviors, which have been positively associated with organizational effectiveness, (Eagly, 2007; Eagly \& Carli, 2003). Indeed, Powell et al. (2008) reported that female transformational leaders were evaluated in more positive terms (i.e., extra effort, satisfaction, effectiveness) when compared with male transactional leaders.

However, organizational context may mediate the positive evaluation of female leaders. In male dominated organizations, those with more men in leadership positions or in more traditionally masculine environments (e.g., military), women were evaluated as less effective than men in leadership positions (Eagly \& Carli, 2003; Eagly, 2007). Intercollegiate athletic administration continues to be dominated by men and men continue to represent the majority of athletic directors $(78.7 \%)$ across all three Divisions of intercollegiate athletics (Acosta \& Carpenter, 2008). Therefore women may be perceived as less effective in leadership positions, regardless of the type of leadership behaviors demonstrated in those positions. This leads us to the following hypotheses:

Hypothesis 2: Regardless of the type of leadership behavior demonstrated, male leaders will be perceived as achieving organizational outcomes (extra effort, satisfaction, and effectiveness) better than female leaders.

Hypothesis 3: Participants will prefer male athletic directors demonstrating transactional leadership behaviors and will prefer female athletic directors demonstrating transformational leadership behaviors, as demonstrated by ratings on organizational outcomes (extra effort, satisfaction, and effectiveness).

\section{Method}

Using an online survey method, athletic directors were provided one of four leadership vignettes for evaluation. A total of $356(N=356)$ current NCAA Division III athletic directors were contacted via e-mail regarding participation in this study. Participants were sent an initial e-mail invitation notifying them that an e-mail would be sent in two days inviting them to participate in an online survey. The e-mail invitation to the survey followed two days later. A reminder e-mail was sent to nonrespondents one week following the e-mail invitation and a second reminder e-mail was sent to nonrespondents two weeks following the e-mail invitation. A total of 98 athletic directors $(n=98)$ completed the survey for a response rate of $27.5 \%$. Thirty-eight women $(39 \%)$ and fifty-eight men responded $(61 \%)$, and the majority of participants identified as White $(93 \%)$. The percentage of men and women responding to the survey closely mirrored the percentage of men and women in the athletic director's position in Division III; Acosta and Carpenter (2008) reported $33.7 \%$ of Division III athletic directors were women.

The leadership vignettes were developed specifically for this study, but were based on previous research that has used transformational and transactional leadership vignettes (Powell et al., 2008). The vignettes depicted a female athletic director as a transformational leader $(n=26)$; a female athletic director as a transactional leader $(n=23)$; a male athletic director as a transformational leader $(n=26)$; and a male athletic director as a transactional leader $(n=23$; Appendix A). 
To assess the leader's behavior in the vignette, participants completed the Multifactor Leadership Questionnaire (MLQ_Form 5×, Bass \& Avolio, 2000). Participants evaluated leader's behavior on eight four-item MLQ subscales that measured different dimensions of transformational leadership behavior (idealized influence-attributes, idealized influence-behavior, inspirational motivation, intellectual stimulation, individualized consideration) and transactional leadership (contingent reward, active management by exception, passive management by exception). Participants rated the leader behavior on a five-point Likert type scale ( 5 = frequently, if not always, $4=$ fairly often, $3=$ sometimes, $2=$ once in a while, $1=$ not at all).

Finally, participants rated outcomes associated with leadership behavior on three subscales (extra effort, satisfaction, and effectiveness). Participants used the same five-point Likert type scale to evaluate outcomes associated with leadership behavior ( $5=$ frequently, if not always to $1=$ not at all). Extra effort was measured on a three-item subscale (e.g., gets subordinates to do more than they are expected to do; $\alpha=.87$ ), a two-item subscale measured satisfaction with the leader (e.g., uses methods of leadership that are satisfying; $\alpha=.83$ ), and a four-item subscale measured leader's effectiveness (e.g., is effective in meeting organizational requirements; $\alpha=.77$ ).

A manipulation check was performed using analyses of variance to examine whether the vignettes actually portrayed transformational and transactional leadership styles. Powell et al. (2008) noted concerns regarding the independence of measures of transformational leadership as assessed in the Multifactor Leadership Questionnaire (MLQ-Form 5×, Bass \& Avolio, 2000). Following the procedures detailed by Powell et al. (2008) to address those concerns, a mean score for transformational leadership was calculated as the average of the five transformational leadership subscales (idealized influence-attributes, idealized influence-behavior, inspirational motivation, intellectual stimulation, individualized consideration). In addition, a mean score for transactional leadership was calculated as the average of the three transactional subscales (contingent reward, active management by exception, passive management by exception). The internal consistency score for the transactional leadership subscale was $(\alpha=.75)$ and for the transformational leadership subscale was $(\alpha=.86)$. A transformational leadership mean score and transactional leadership mean score were calculated for both the transactional leadership vignette and the transformational leadership vignette (Table 1). Results of the ANOVAs indicated that the vignettes successfully portrayed transactional leadership and transformational leadership as intended. Participants indicated the leader in the transactional leadership vignette demonstrated more transactional leadership behaviors $(\mathrm{M}=3.14)$ compared with the transactional leadership behaviors demonstrated by leaders in the transformational leadership vignette $(\mathrm{M}=2.54), \mathrm{F}(1,96)=28.9, p<.001$. Similarly, participants indicated the leader in the transformational leadership vignette demonstrated more transformational leadership behaviors $(\mathrm{M}=4.17)$ compared with the transformational leadership behaviors demonstrated by leaders in the transactional leadership vignette $(\mathrm{M}=$ 3.67), $\mathrm{F}(1,96)=20.72, p<.001$.

Also, in an effort to address the limitation of lower response rate, a wave analysis was undertaken to examine differences between early and later respondents. Wave analysis is recommended as an analytic tool to look for nonresponse bias 


\section{Table 1 Means and Standard Deviation Scores on the MLQ for Transactional and Transformational Leadership Vignettes}

\begin{tabular}{lcc}
\hline & \multicolumn{2}{c}{ MLQ Scores } \\
\hline Type of Leadership Vignette & Transactional Scores & Transformational Scores \\
\hline Transactional Leaders & $3.14(S D=.57)$ & $3.67(S D=.58)$ \\
Transformational Leaders & $2.54(S D=.52)$ & $4.17(S D=.50)$ \\
\hline
\end{tabular}

in survey research by examining differences in early and later responders. If late respondents differ from early respondents, this may suggest some level of nonresponse bias in the survey (Rogelberg \& Stanton, 2007). Responses submitted within the first few days of the initial e-mail notification were considered early responders and were compared with late responders, those who completed the survey at least two weeks following the initial e-mail. Comparisons were conducted for all dependent variables (i.e., extra effort, effectiveness, satisfaction) and no significant differences were revealed at the $p<.05$ or $p<.001$ level.

\section{Results}

Descriptive statistics for perceived organizational outcomes for transactional and transformational leadership are provided in Table 2. Multivariate analysis of variance was used to evaluate hypotheses 1-3. The independent variables included in the analysis were type of leadership style and gender of leader (transactional male, transactional female, transformational male, transformational female), evaluator's gender, and the interaction of gender and leadership style and evaluator's gender. Dependent variables evaluated in the analysis were the outcomes associated with leader's behavior (extra effort stimulated by the leader, satisfaction with the leader, and leader's effectiveness). The overall MANOVA was not significant (Table 3). However, in evaluation of Hypothesis 1, that transformational leadership style, when compared with transactional leadership style, would lead to more positive perceptions of organizational outcomes as demonstrated by the leader (extra effort, satisfaction, and effectiveness), results indicated a main effect for transformational leadership, Wilkes $\lambda=.75, \mathrm{~F}(9,210)=2.87, p=.003$. Follow-up univariate analyses of variance indicated that transformational leaders were evaluated more favorably on extra effort, $\mathrm{F}(3,94)=8.19, p<.001$ and satisfaction, $\mathrm{F}(3,94)=4.22, p<.05$, but not on effectiveness $\mathrm{F}(3,94)=1.92, p=.13$.

Post hoc analyses using Tukey's HSD examined type of leadership behavior (transactional or transformational) and gender of leader on perceived organizational outcomes. Hypothesis 2 stated that regardless of the type of leadership behavior demonstrated, male leaders will be perceived as achieving organizational outcomes (extra effort, satisfaction, and effectiveness) better than female leaders. However, results revealed that both male and female transformational leaders provided better organizational outcomes when compared with male and female transactional leaders (see Table 2). Our third hypothesis posited that participants would prefer male 
Table 2 Means and Standard Deviations (SD) for Dependent Variables by Male and Female Evaluator

\begin{tabular}{llcc}
\hline $\begin{array}{l}\text { Dependent } \\
\text { Variable }\end{array}$ & Leadership Style & $\begin{array}{c}\text { Male Evaluator } \\
\text { Mean (SD) }\end{array}$ & $\begin{array}{c}\text { Female Evaluator } \\
\text { Mean (SD) }\end{array}$ \\
\hline Extra effort & Male transactional & $3.74(.84)$ & $3.74(.77)$ \\
& Male transformational & $4.33(.45)$ & $4.37(.92)$ \\
& Female transactional & $3.67(.83)$ & $3.77(.44)$ \\
& Female transformational & $4.41(.69)$ & $4.48(.53)$ \\
Satisfaction & Male transactional & $3.96(1.0)$ & $3.83(.75)$ \\
& Male transformational & $4.30(.62)$ & $4.37(1.18)$ \\
& Female transactional & $3.71(.87)$ & $4.11(.74)$ \\
& Female transformational & $4.57(.53)$ & $4.54(.54)$ \\
Effectiveness & Male transactional & $3.98(.73)$ & $3.92(.43)$ \\
& Male transformational & $4.05(.74)$ & $4.46(.77)$ \\
& Female transactional & $3.98(.74)$ & $3.86(.58)$ \\
& Female transformational & $4.34(.74)$ & $4.31(.53)$ \\
\hline
\end{tabular}

Table 3 Multivariate Analysis of Variance for Leadership Vignette (Type of Leadership and Gender of Leader) x Evaluator Gender on Leader Outcomes

\begin{tabular}{|c|c|c|c|c|}
\hline \multirow[b]{2}{*}{ Source } & \multirow[b]{2}{*}{$\begin{array}{c}\text { Multivariate } \\
F(9,210)\end{array}$} & \multicolumn{3}{|c|}{ Univariate } \\
\hline & & $\begin{array}{c}\text { Extra effort } \\
F(3,94)\end{array}$ & $\begin{array}{c}\text { Satisfaction } \\
F(3,94)\end{array}$ & $\begin{array}{c}\text { Effectiveness } \\
F(3,94)\end{array}$ \\
\hline \multicolumn{5}{|l|}{ Main effects } \\
\hline Leadership vignette & $2.87 *$ & $8.19 * *$ & $4.22 *$ & 1.92 \\
\hline Gender of evaluator & .068 & .13 & .12 & .21 \\
\hline Interaction effect & & & & \\
\hline $\begin{array}{l}\text { Leadership vignette } \\
\mathrm{x} \text { gender of evaluator }\end{array}$ & 1.43 & .02 & .75 & .47 \\
\hline
\end{tabular}

$* \mathrm{p}<.05, * * \mathrm{p}<.001$

athletic directors demonstrating transactional leadership behaviors and would prefer female athletic directors demonstrating transformational leadership behaviors, as demonstrated by ratings on organizational outcomes (extra effort, satisfaction, and effectiveness). Results revealed that there were no significant main effects other than transformational leadership, and that the gender and leadership style $\mathrm{x}$ gender of evaluator interaction was not significant. Participants did not indicate 
more positive perceptions of the male athletic director as a transactional leader nor did they indicate more positive perceptions of the female athletic director as a transformational leader.

\section{Discussion}

Overall, male and female transformational leaders were evaluated more favorably on two dimensions of leadership behavior when compared with transactional leaders. Thus, in partial support of our first hypothesis, and consistent with previous business management research (Powell et al., 2008) and some research in sport management (Choi et al., 2007; Doherty \& Danylchuk, 1996), transformational leadership was the preferred leadership style for satisfaction with the leader and extra effort stimulated by the leader. However, unlike previous findings, transformational leadership was not evaluated more favorably than transactional leadership on leader effectiveness, and thus support for this hypothesis must be tempered. As transactional leadership is associated with task-focused behavior (Yukl, 1999), perhaps transactional leadership was perceived as equally valuable with regards to effectiveness in an intercollegiate athletic department context requiring a high degree of detail-oriented work, such as schedule coordination, team travel, facility operations and myriad other tasks, more so than in other work contexts. As such, these results not only speak to the value of fostering transformational leadership to achieve positive organizational outcomes, but to also recognizing that transactional, task-focused leader behavior could be used in complement with transformational leadership to achieve some outcomes in the intercollegiate context.

We found no support for our second hypothesis, which stated that regardless of the type of leadership behavior demonstrated, male leaders will be perceived as achieving organizational outcomes (extra effort, satisfaction, and effectiveness) better than female leaders. In addition, we did not find support for our third hypothesis that participants will prefer male athletic directors demonstrating transactional leadership behaviors and will prefer female athletic directors demonstrating transformational leadership behaviors. Overall, transformational leadership was preferred with regard to satisfaction and extra effort demonstrated by the leader, and both transactional and transformational leaders were supported for leader effectiveness. Thus, unlike previous business management research (Eagly \& Karau, 2002; Powell et al., 2008), role congruent leaders (female leaders demonstrating transformational leadership, masculine leaders demonstrating transactional leadership) were not evaluated more favorably than gender role incongruent leaders (female leaders demonstrating transactional leadership, masculine leaders demonstrating transformational leadership).

Therefore, results do not suggest a female advantage when demonstrating transformational leadership at the Division III level. Situational specificity may help explain these findings. The participants in this research project were athletic directors for Division III athletic programs, which have specific missions, objectives and goals that may align more closely with the tenets of transformational leadership. For example, the following synopsis of Division III athletic programs' objectives outlines specific values and goals related to transformational leadership: 
Colleges and universities in NCAA Division III place highest priority on the overall quality of the educational experience and on the successful completion of all students' academic programs. They seek to establish and maintain an environment in which a student-athlete's athletics activities are conducted as an integral part of the student-athlete's educational experience. They also seek to establish and maintain an environment that values cultural diversity and gender equity among their student-athletes and athletics staff (NCAA, 2009).

As the objectives of Division III athletics encompass a focus on the student-athlete and valuing relationships and the entire educational experience, transformational leadership, with its emphasis on individualized consideration and relationships, could be preferred to transactional leadership behaviors regardless of gender. In essence, transformational leadership could be perceived as being more important to the organizational objectives of the program, thus leading to the perception that transformational leadership is better suited to achieving positive organizational outcomes in this setting. In addition, $33.7 \%$ of athletic directors at the Division III level are female (Acosta \& Carpenter, 2008), and Doherty (1997) notes that female athletic directors more often demonstrate transformational leadership behaviors. Thus, at the Division III level, females could be more accepted in leadership roles, and hence, females as well as males displaying transformational leadership behaviors may be perceived as obtaining positive organizational outcomes better than leaders exhibiting transactional leadership behaviors.

It must also be noted that in Powell et al.'s study (2008), which found that role congruent leaders were evaluated more favorably than role incongruent leaders, the sample consisted of part-time MBA students. Likely, many of these students were working in or had aspirations to work in the mainstream corporate sector, which has traditionally been the purview of male leaders displaying transactional leadership. Thus, they could have been preconditioned to expect male leaders to exhibit transactional leadership behaviors, and female leaders to display transformational leadership behaviors, consistent with role congruity theory. In the current study, however, the participants were Division III athletic directors, who may have a different orientation toward leadership preferences than those working in the corporate sector. If these athletic directors align with the objectives and mission of Division III athletics, as outlined earlier, they may then value transformational leadership behaviors over transactional, regardless of whether it is a male or female leader they are evaluating.

However, the results could be different in a Division I or II setting, or in other segments of the sport industry. For instance, as mentioned previously, in male dominated organizations, those with more men in leadership positions or in more traditionally masculine environments (e.g., military), women were evaluated as less effective than men in leadership positions (Eagly \& Carli, 2003; Eagly, 2007). It can be argued that Division I is historically a male-dominated segment of the sport industry, with many more men than women in key leadership positions. For example, Division I has the lowest percentage of women in the role of athletic director (8.4\%; Acosta \& Carpenter, 2008). Hence, in the Division I or even Division II setting, female leaders could be evaluated as less effective in achieving organizational outcomes than male leaders. 


\section{Practical Implications}

The key managerial implication is that both male and female athletic directors, as well as others in leadership in intercollegiate athletics, should strive to display transformational leadership behaviors to better achieve organizational outcomes. By providing individualized consideration and valuing employees as individuals, and by celebrating their accomplishments and achievements, leaders can stimulate extra effort from employees, which could translate into greater efficiency and increased organizational performance. In addition, employees may be more satisfied with their leaders if transformational leadership is displayed, which could then motivate higher levels of organizational commitment and reduce turnover intentions.

\section{Limitations}

Though the findings from the current study make important contributions to the understanding of leadership in athletic administration, there are some limitations that must be noted. First, a low response rate was reported $(27.5 \%)$, indicating the findings must be interpreted with caution. However, in an effort to address this limitation, it was noted that the percentage of male and female sample participants in the current study did closely represent the number of men and women athletic directors at Division III colleges and universities. In addition, wave analysis was used to attempt to evaluate if late responders (often thought to be similar to nonresponders) differed significantly from early responders. No differences were revealed in the wave analysis. An additional limitation was the use of a vignette to evaluate leadership outcomes. Though we provided a detailed description of the leader and her/his behavior in the scenario that was based on previous work evaluating transactional and transformational leadership (Powell et al., 2008), this was not an evaluation of actual leadership behavior in a real world setting. In addition, previous research has noted that transactional and transformational leadership consists of multiple dimensions, and the use of vignettes depicting leaders as transactional or transformational does not allow for individual differences in leadership behavior along these multiple dimensions to be revealed (Bass, 1985; Powell et al., 2008). Finally, use of athletic directors, that is, use of current leaders may not have been the most suitable sample for evaluation of leader preferences. Preference of leader behaviors as evaluated by subordinates within the athletic department may have yielded different results. This limitation will be addressed in the subsequent section regarding future research directions.

\section{Future Research Directions}

Several recommendations for future research emerged from this study. First, there is a need to replicate the current study in the Division I and II context, as well as in the NAIA and other segments of the sport industry, to see if similar results are obtained, or if findings may vary depending on context. Results of future research in different types of athletic departments may provide information to better understand if the context of athletic administration and the way athletic departments are constituted have impacts on the type of leadership deemed appropriate. In addition, 
this study should be replicated with subordinates within intercollegiate athletic administration. Subordinates would include director level positions (e.g., marketing, compliance, operations directors), coaches, and support staff. Another direction for future research is to assess preferences for transformational and transactional leadership against other organizational outcomes, such as job satisfaction, organizational performance, organizational commitment, and turnover intentions. It could be that leadership style preferences and/or preferences for leadership style as related to gender may change based on the organizational outcomes being measured. In addition, in the Division III context, future research is needed to help uncover the determinants of transformational leadership preferences, and why role congruity theory did not hold in this setting. Finally, perhaps leadership preferences and/or preferences for leadership style as related to gender will change based on the level and role of the employee.

\section{Conclusion}

In conclusion, the purpose of this study was to determine whether leadership style (transactional or transformational) led to more positive perceptions of organizational outcomes in intercollegiate athletic administration and whether gender of the leader influenced these perceptions. Its main contribution was to extend role congruity theory into the intercollegiate athletic context by replicating the work of Powell et al. (2008). The key take away is that male and female transformational leaders were preferred overall, and were perceived as obtaining organizational objectives better than transactional leaders.

\section{References}

Acosta, R.V., \& Carpenter, L.J. (2008). Women in intercollegiate sport: A longitudinal study thirty-one year update (1977-2008). Retrieved June 25, 2009 from http://webpages. charter.net/womeninsport.

Bass, B.M. (1990). From transactional to transformational leadership: Learning to share the vision. Organizational Dynamics, 18(3), 19-31.

Bass, B.M. (1985). Leadership and performance beyond expectations. New York: Free Press.

Bass, B.M., \& Avolio, B.J. (2000). Multifactor Leadership Questionnaires: Technical report, leader form, rater form, and scoring key for MLQ Form $5 X$-Short (2nd ed.). Redwood City, CA: Mind Garden.

Bryman, A. (1992). Charisma and leadership in organizations. London: Sage.

Burns, J.M. (1978). Leadership. New York: Harper \& Row.

Choi, J., Sagas, M., Park, S., \& Cunningham, G.B. (2007). Transformational leadership in collegiate coaching: The effects of transformational leadership on job satisfaction, organizational commitment, and organizational citizenship behavior. International Journal of Sport Management, 8(4), 429-445.

Doherty, A.J. (1997). The effect of leader characteristics on the perceived transformational/ transactional leadership and impact of interuniversity athletic administrators. Journal of Sport Management, 11, 275-285.

Doherty, A.J., \& Danylchuk, K.E. (1996). Transformational and transactional leadership in interuniversity athletic management. Journal of Sport Management, 10, 292-310.

Eagly, A.H. (2007). Female leadership advantage and disadvantage: Resolving the contradictions. Psychology of Women Quarterly, 31, 1-12. 
Eagly, A.H. (1987). Sex differences in social behavior: A social-role interpretation. Hillsdale, NJ: Erlbaum.

Eagly, A.H., \& Karau, S.J. (2002). Role congruity theory of prejudice toward female leaders. Psychological Review, 109, 573-598.

Eagly, A.H., Johannesen-Schmidt, M.C., \& van Engen, M.L. (2003). Transformational, transactional, and laissez-faire leadership styles: A meta-analysis comparing women and men. Psychological Bulletin, 129, 569-591.

Eagly, A.H., \& Carli, L.L. (2003). Finding gender advantage and disadvantage: Systematic research integration is the solution. The Leadership Quarterly, 14, 851-859.

Eagly, A.H., Wood, W., \& Diekman, A.B. (2000). Social role theory of sex differences and similarities: A current appraisal. In T. Eckes \& H.M. Trautner (Eds.), The Development Social Psychology of Gender. New Jersey: Lawerence Erlbaum Associates.

Heilman, M. E. (2001). Description and prescription: How gender stereotypes prevent women's ascent up the organizational ladder. Journal of Social Issues, 57, 657674.

Judge, T.A., \& Piccolo, R.F. (2004). Transformational and transactional leadership: A metaanalytic test of their relative validity. The Journal of Applied Psychology, 89, 755-768.

Kent, A., \& Chelladurai, P. (2001). Cascading transformation leadership, organizational commitment, and citizenship behavior: A case study in intercollegiate athletics. Journal of Sport Management, 15, 135-159.

Kuhnert, K.W., \& Lewis, P. (1987). Transactional and transformational leadership: A constructive developmental analysis. Academy of Management Review, 12, 648657.

National Collegiate Athletic Association. (2009). Retrieved June 29, 2009 from http:// www.ncaa.org/wps/ncaa?key=/ncaa/ncaa/legislation+and+governance/committees/ division3.html.

Powell, G.N., Butterfield, D.A., \& Bartol, K.M. (2008). Leader evaluations: a new female advantage? Gender in Management: An International Journal, 23(3), 156-174.

Powell, G.N., Butterfield, D.A., \& Parent, J.D. (2002). Gender and managerial stereotypes: have the times changed? Journal of Management, 28(2), 177-193.

Rogelberg, S. G., \& Stanton, J. M. (2007) Introduction: Understanding and dealing with organizational survey non-response. Organizational Research Methods, 10, 195209.

Schein, V.E. (2001). A global look at psychological barriers to women's progress in management. The Journal of Social Issues, 57, 675-688.

Stewart, G.L. (2006). A meta-analytic review of relationships between team design features and team performance. Journal of Management, 32(1), 29-55.

Wallace, M., \& Weese, W.J. (1995). Leadership, organizational culture, and job satisfaction in Canadian YMCA organizations. Journal of Sport Management, 9, 182-193.

Weese, W.J. (1996). Do leadership and organizational culture really matter? Journal of Sport Management, 10, 197-206.

Yukl, G. (1999). An evaluation of conceptual weaknesses in transformational and charismatic leadership theories. The Leadership Quarterly, 10, 285-305.

\section{Appendix A}

Adapted for an athletic administration prospective based on the work of Powell, Butterfield \& Bartol (2008)

\section{Transformational Vignette}

Following several embarrassing scandals (recruiting violations, illegal athletic booster activity, student-athlete legal issues) within the athletic department, a new athletic director, Joan (John) Barkley was hired by State University to lead the 
Division I BCS athletics program. Joan (John) has long been recognized by colleagues and friends as a highly optimistic individual. Generally speaking, those who spend any time with her (him) become infected by her (his) enthusiasm. A former associate athletic director working under Joan (John) remarked:

Whenever you're around Joan (John) you can't help but feel good. She (he) pays close attention to your personal needs for achievement and growth. In addition, Joan (John) encourages you to be innovative and creative (while remaining within the guidelines of NCAA regulations) in your work; she (he) says that you should never rely on the 'tried and true' and always approach old problems in new ways. As a result, Joan (John) makes you feel like you can accomplish anything.

Other colleagues at Joan's (John's) previous university remarked that they have never worked in an athletic department so devoted to its leader and her (his) vision. Before Joan's (John's) taking over at State University, most associate and assistant directors were confused about their roles and responsibilities in the athletic department and were hoping that potential scandals would not result from the lack of effective leadership. Since Joan (John) took over people have become inspired by what the future will bring. State University still has to deal with NCAA sanctions, but the associate and assistant directors in the department have rallied around Joan's (John's) radically different and inspirational vision.

One area where Joan (John) has been particularly successful was in calming the concerns of the University President and Board of Trustees. During a recent meeting of the President and Board, Joan (John) demonstrated her (his) excellent communication skills. One Board member related the experience as follows:

Just before the meeting was about to start, the mood was extremely dour, explosive I might add. So then in comes Joan (John), calmly and confidently walking into the meeting. By the end of her (his) 45-minute address to the group, we were all mesmerized. Now, as I think about it, we didn't get the answers we wanted, but most board members are excited about the direction Joan (John) wants to take the athletic department.

\section{Transactional Vignette}

Following several embarrassing scandals (recruiting violations, illegal athletic booster activity, student-athlete legal issues) within the athletic department, a new athletic director Joan (John) Barkley was hired by State University to lead their Division I BCS athletics program. Joan (John) has long been recognized by colleagues and friends as a highly focused individual. Generally speaking, those who spend any time with her (him) feel that they have been appropriately rewarded or disciplined depending on the adequacy of their performance. A former associate athletic director working under Joan (John) remarked:

Whenever you're around Joan (John) you know you will be rewarded if (and only if) you meet your assigned objectives. Joan (John) always follows through on promises of rewards when we successfully complete our assignments. Joan (John) also lets us know when we do not meet performance standards. She 
(he) doesn't do anything further about little slips on our part, preferring to let us resolve minor problems on our own. On the other hand, when problems become serious, we know that she (he) will step in and take whatever corrective action is needed.

Other colleagues at Joan's (John's) previous university remarked that they have never worked in an athletic department so focused on subordinate performance. Before Joan's (John's) taking over at State University, most associate and assistant directors were confused about their roles and responsibilities in the athletic department and were hoping that potential scandals would not result from the lack of effective leadership. Since Joan (John) took over people have begun to think that the difficulties will be resolved, one way or another. State University still has to deal with NCAA sanctions, but the associate and assistant directors in the department have rallied around Joan's (John's) deliberate management style.

One area where Joan (John) has been particularly successful was in calming the concerns of the University President and Board of Trustees during the annual athletic department performance review. Joan (John) demonstrated that the athletic department is better off when it implements incentives for good performance (within each department) and addresses performance problems before they get out of hand. One associate director said:

I felt my meeting with Joan (John) went well. The objectives we set for next year are reasonable. Her (his) criticisms about some low points last year were fair, and I got positive strokes for the high points. I like knowing where I stand, and being rewarded accordingly.

Other associate and assistant directors agreed. 